\title{
Sub-Saharan Africa's Perspective of distance learning
}

\author{
Nirmal Kumar Betchoo* \\ Université des Mascareignes, Rue de la Concorde, Beau Bassin-Rose Hill, Mauritius \\ *E-mail address: nbetchoo@udm.ac.mu, betchoonirmal@yahoo.com
}

\begin{abstract}
This review article follows the author's participation in the International DEASA Conference held in Mauritius in December 2014. There is a growing concern over the years to develop Open and Distance Learning (ODL) in sub-Saharan Africa based upon the fact that all nations are connected to the Internet and related technologies. In this perspective, the objective of encouraging distance learning comes from the fact that it had existed in Mauritius and several other countries in its traditional form through mail and correspondence courses. The fact that such type of education is gaining more recognition today calls the author to reflect upon how suitably distance education could be imparted in sub-Saharan Africa with the knowledge that it is still in its infancy since Africa is in general lagging behind in technology. There is no excuse given that governments in sub-Saharan Africa believe that distance learning helps building capacity in their respective countries and favours the advancement and growth of individuals. Blending both technology and education followed by governing principles of broadening educational access at the tertiary level might improve opportunities for development and growth. Illustrations are taken from different countries which have both met with the challenges and success of distance learning. It is found out that governments in sub-Saharan Africa need to move forward with bolder initiatives to ensure the success of open and distance learning in the region.
\end{abstract}

Keywords: sub-Saharan Africa; open and distance learning; education

\section{INTRODUCTION}

The $49^{\text {th }}$ DEASA Conference jointly held by the Distance Education Association of Southern Africa and the Open University of Mauritius from the $4^{\text {th }}$ to $7^{\text {th }}$ December 2014 was an interesting platform on distance learning in sub-Saharan Africa which is now a region for the development and growth of learning opportunities. For instance, Nigeria, which is Africa's biggest economy and has the largest African population, is leading the growth of new middle-class households on the continent with an estimated 7.6-million to be added in the next 16 years [1]. With a growing middle class having better access to education, subSaharan Africa will definitely make important advancements in this field. Rapid expansion in higher education, coupled with moderate growth in suitable employment opportunities in recent years, has resulted in considerable unemployment among recent university graduates in a number of Sub-Saharan African countries [2]. The objective of the conference held in Mauritius focused on Open and Distance learning for sustainable development with emphasis on innovative learning, research and the need to expand distance learning opportunities 
within the region [3]. The DEASA itself contributes towards higher professionalism and the advancement of distance education and to share capacity building initiatives in SADC member states.

\subsection{The early form of distance learning}

If someone looks back at distance learning from a Mauritian perspective, he/she would recall those days when distance learning was popularly expressed as 'correspondence course' pioneered by the University of London, Wolsey Hall Oxford and the Rapid Results College. For example, Wolsey Hall has a long history of providing home study courses to adult learners. Since its foundation in 1894 over 750,000 students have gained qualifications and many have gone on to higher education or improved their career prospects as a result [4]. The Rapid Results College viewed distance learning as a very cost-effective option and gives you the flexibility to study when and where suits you best [5]. These institutions took into consideration the importance of sustainable development by developing learning programmes for people at work and who could not afford taking leave without pay to learn in England or any other European country. Obviously, correspondence courses focused on academic subjects like Accounting. Mathematics, Business including English language which were never offered as degree-based programmes in Mauritius. One could then hear of graduates having done their BA Inter, Matric or any other programme through distance learning.

\subsection{The low profile of distance learning}

Despite the fact that correspondence courses met the needs of a niche market of enthusiastic learners who obtained diplomas and certificates without going to a university, such qualifications were usually questioned by employers and the Public Service Commission as being 'low value' or ordinary qualifications compared to the prestige of stepping into a university with its faculty, alumni and the range of activities and programmes prior to completing a degree. In the early $1950 \mathrm{~s}$, despite the efforts of leaders in the field, correspondence study struggled to gain acceptance, and it was still seen as suspect by academics [6]. Correspondence courses were meant for the lower middle class and those not having the exacting qualifications to earn a degree. Added to these was the low pass rate through distance education where students ceased to learn from a lack of support after failing in some introductory courses. Initially, the medium of mail was a dominate delivery system for over forty years, but new delivery technologies started to provide additional options for correspondence study [7].

\subsection{The development of Open and Distance Learning platforms}

By skipping directly to the present situation, correspondence courses have been revamped as distance learning programmes. It is though the development of the Internet and Information and Communication Technologies (ICT) that distance learning has become all of a sudden a vital tool for education. Universities from Europe were sceptical of this idea maintaining that traditional attendance and instruction from their campus was a means to show how prestigious and unique their qualification was.

Nowadays in Europe, the educational system reforms encourage further discussion on the comparability of curricula in terms of structures, programs and actual teaching as well as inseparable linking credits and learning outcomes, expressed in terms of competence [8]. Step 
by step, universities have been re-engineered towards ODL organizations. As a less risky approach they apply blended methodology in education and develop university services online. They include e-libraries, instructional networking and computing, media services, the campus course catalogue and schedule, multimedia courseware production [9].

New universities sprouted in the face of the inertia of traditional universities. By developing online and regional accreditation, such universities grew as new hubs for learning. The University of Phoenix, Walden University were among the first to move to Masters and eventually Doctorate programmes followed by others from Europe choosing ACBSP accreditation for distance learning programmes. Accreditation, in itself, adds value to an education institution's systems and gives both the local public and international higher education community confidence in your programmes, whatever the delivery mode. Accreditation is advantageous to both educators and students, and helps ensure wider acknowledgement and transferability of the qualifications and credits your institution confer [10]. Since these institutions reaped success, many traditional universities started to develop a variety of distance learning programmes.

\section{THE AFRICAN PERSPECTIVE OF OPEN AND DISTANCE LEARNING}

It may be naïve to state that sub-Saharan Africa has stayed behind in this avenue. Regarding correspondence courses, University of South Africa (UNISA) stands as the most successful university in this field offering correspondence courses since the 1890 s and widening their access to the Southern African Development Community.

The unique offering of UNISA could not be contested because other countries could not afford offering hundreds of programmes in different fields. In a period of apartheid, UNISA could challenge the segregation system by offering access to any student regardless of his race, gender or colour. UNISA committed itself to advancing social justice with an emphasis on redress, equity and empowerment of the previously disadvantaged groups in South Africa such as blacks, women, and people with disabilities, the rural and urban poor and adults generally who have missed out on opportunities to access higher education [11]. This is a fascinating area where distance learning overcame barriers to learning.

\subsection{Open and Distance learning adapted to Africa}

The development of the Internet could not leave any African institution 'on the bench' or staying as laggard in the area of distance learning. DEASA as an independent organisation has organised International Conferences to sensitise public opinion on the importance of education within sub-Saharan Africa. Internet entered the region in a short time lapse compared to developed nations but was accessible only to the rich at the beginning. In SubSaharan Africa, however, where it is estimated that only 1 in 250 people have access to the Internet as against the global average of 1 in 15 online learning in higher education poses a great challenge as this mode of instruction delivery relies solely on the available information and communication technology infrastructure [12]. The divide between the rich and the lower classes was gradually bridged through the creation of platforms like Wi-Fi, cloud computing, Skype, and a panoply of social networks like Facebook, etc.

Although there was questioning about the informal nature of such Open and Distance Learning platforms regarding security, communication breakdowns, hacking to the system, among others, the distance learning concept emanated as some novel way of developing and 
broadening education access to sub-Saharan Africa. Online learning is thus being rapidly adopted by educational institutions worldwide as an alternate or complementary mode of education delivery, and indeed has been heralded as the next democratizing force in education, particularly in higher education [13].

Mauritius, being one of the most developed nations, took an important initiative by creating the Open University, a similar concept to the Open University UK, from its earlier concept 'Mauritius College of the Air' which initiated correspondence courses through learning materials and audio-visual production. Around the world, the number of students wishing to pursue higher education is increasing and a similar trend has been noted in Mauritius. The number of students enrolled increased by $8 \%$ during one year to reach nearly 50,000 in 2012/2013. The Gross Tertiary Enrolment Rate was estimated at $46.6 \%$ for the year 2013. One out of every five student chose to study abroad and the remaining chose to study in one of the 65 local tertiary education institutions [14]. In today's context, the programmes stretch from tailor-made courses for corporations to Doctorate programmes. In Mauritius, demand for continuing education for groups of learners such as housewives, employed women, out of school youths and functionally illiterate persons is increasing. The survival of a healthy and multicultural democratic society depends on whether the education system can respond to this pressure quickly and adequately [15]. In another manner, the University of Mauritius through its Centre for Virtual Learning offers both stand-alone and full-fledged degree programmes.

At the sub-Saharan African level, development is underway with universities embracing distance learning after being shielded from traditional on-campus attendance. There is growing recognition of the need to build learner support into distance learning programmes, especially for learners entering higher education from schooling systems which have not prepared them for independent study. By and large, support is offered either through face-to-face contact sessions or, in a more limited way, using telecommunications, audio and video strategies [16].

Taking into consideration that young Africans are more literate than their elders and that the diffusion of technology through mobile phones and other support systems like Internet, cable technology and satellite transmission has become a reality, institutions of higher learning now appreciate the importance of distance learning. Almost 20 percent of Africans have Internet access through broadband connections on mobile phones, according to the International Telecommunications Union [17].

\section{BUILDING CAPACITY IN SUB-SAHARAN AFRICA}

Far from considering distance learning as degrading and of low value, sub-Saharan African governments now value this concept. Illiteracy is still high among the huge young population of Africa and without education, the region would fail. This alarm signal has encouraged African universities to react and become pro-active. A striking example of the powerful effect of this combination of education and communications infrastructure is the network of distance learning centres that has been built up across Africa. The centres are local and regional communication hubs, which facilitate knowledge-sharing, education and training for leaders and professionals in the private, public, civil society and NGO sectors [18]. Capacity building firstly relates to developing capable and learned individuals who can 
enter the job market but also fulfil the higher-skilled jobs that are now in demand in Africa. Secondly, there are areas where capacity could be consolidated. These could be in sectors like teaching and research, information technology and new sectors demanding skills like environmental and sustainable development, ecological development, etc.

Distance learning in sub-Saharan Africa becomes an opportunity since education can be offered in different ways. Tailor-made programmes for corporates and individuals develop special and focused learning for this audience with ready-made skills for specific jobs. Academic programmes could develop capacity for individuals looking for higher-ranked jobs. There might also be the possibility of creating courses for employability. It should be noted that before sub-Saharan Africa states can cross the "digital divide", they must traverse the divide between the more and the less technologically advanced countries. Sub-Saharan African states fall into the latter category. One of the manifestations of this divide is the wide gap between the telecommunication infrastructure of developed and developing countries [19].

\section{CONCLUSION}

Since traditional learning limited the number of graduates, open learning could look for other objectives but essentially pursue the key founding principle-sustainable development. More and more people need to be trained and as the population of sub-Saharan Africa rises, more people will need education. Kinyanjui (1998) emphasises that governments and distance education associations should work together to identify common issues and challenges facing sub-Saharan Africa. This will help them to develop appropriate strategies and policies for distance education and open learning at national, regional and international levels [20]. Open learning broadens this avenue by offering learning platforms for long-term, hence sustainable development. Either through sponsored or self-financed learning, open learning democratises education without raising too formal barriers to entry.

Trends in online education stand to have profound impacts on employment, culture, communication and class around the world. The rapid global expansion in online education resources will make learning opportunities more abundant, cheaper and more accessible. Increased value placed on lifelong learning and the recognition of non-formal and informal learning will change the nature of recruitment, and equalise employment opportunities in a number of ways [21].

We might unfortunately live in an ultra-competitive world boasting the elites or the 'cream' of society but DEASA's commitment to open and distance learning must be saluted. This can range from the peasant ploughing the fields in Rwanda to the top brass executive demanding a Master's programme in Corporate Financing in Pretoria. It is against this back drop that Open and Distance Learning (ODL) has been identified as the panacea to the perennial educational challenges of equitable access to learning, equality of educational opportunities as well as providing a second chance for those who had never been or had once been in the system but had to drop out for one reason or another [22]. There is a place for everyone and through education without fear, duly supported by open and distance learning, capacity building in Africa might not be a myth. 


\section{References}

[1] Standard Bank Team (2014), Rise of the middle class in sub-Saharan Africa.

[2] Majgaard, K. and Mingat, A. (2012) Education in Sub-Saharan Africa, A Comparative Analysis, World Bank Report.

[3] 49th DEASA Conference: "Open and Distance Learning (ODL): Towards sustainable development in the Southern African Development Community (SADC) Region", Distance Education Association of Southern Africa (DEASA).

[4] Wolsey Hall, the Home Study College (2014), http://wolseyhalloxford.org.uk/, Retrieved on $15^{\text {th }}$ January 2015

[5] RRC International (2014)http://www.rrc.co.uk/about-us/learning-with-rrc/distancelearning.aspx, Retrieved on $16^{\text {th }}$ January 2015

[6] Nasseh, B. (1997) A brief history of distance education, Bill State University.

[7] Pankowska, M. (2006) Value development at Online Distance Learning University, Journal of Theoretical and Applied Electronic Commerce Research, ISSN 0718-1876 VOL 1, Issue 3, December 2006, pp 28 - 41 Ibid.

[8] Kilfoil, W. (2007) Acquiring accreditation in distance learning, Commonwealth of Learning.

[9] Strategic Plan of UNISA (2015) Open and Distance learning, University of South Africa.

[10]UNESCO Institute for Statistics. (2007). Global education digest 2006: Comparing education statistics across the world.

[11]Jones, G. R. (1997) Cyberschools, Englewood, CO: Jones Digital Century.

[12] Open and Distance Learning : Key to making Mauritius a Knowledge Hub (2014) News on Sunday, Friday $15^{\text {th }}$ August 2014.

[13]Rumajogee, R. (2001) Distance Education: A logic of diffusion or a logic of service? (A Mauritian Experience). Ph.D. thesis, University of Paris 8, Department of Education Studies.

[14] Commonwealth of Learning (2002) Distance Education and Open learning in SubSaharan Africa, A literature survey on policy and practice.

[15] Young African Leaders Initiative (2014) Is an Open Internet important to you? US Department of State.

[16] How distance learning has enabled capacity building in Africa, http://www.elearningafrica.com/press_releases_html/pr_2014_08.html Retrieved on $3^{\text {rd }}$ February 2014

[17] Ivala. E. 1999. The Internet and Distance Education. A paper presented at the $1^{\text {st }}$ National NADEOSA Conference, 11-13 August 1999.

[18] Kinyanjui, P. E. (2000) Future Trends in Open and Distance Education, in Huria Journal of the Open University ofTanzania, Volume III, No. 1, September, 2000. 1 - 10. 
[19] Online Education will Democratise and Disrupt Global Learning (2013), Trends, IFLA.

[20] Ofoegbu, F. and Ojogwu, open distance learning (odl) as a mechanism for sustainable female education in Nigeria, http://www.emasa.co.za Retrieved on $6^{\text {th }}$ February 2015. 